\title{
A importância do Programa de Monitoria no ensino de Biblioteconomia da Universidade do Estado de Santa Catarina (UDESC)
}

\author{
The Importance of Monitoring Program in teaching Librarianship from the Universidade do \\ Estado de Santa Catarina (UDESC)
}

\begin{abstract}
Eduardo Silveira
Doutorando em Ciência da Informação pelo Programa de pós-graduação em Ciência da Informação da Universidade Federal de Santa Catarina PGCIN/UFSC.

E-mail: edusilveira1985@gmail.com
\end{abstract}

Fernanda de Sales

Doutoranda em Educação pelo Programa de Pós-Graduação em Educação da Universidade do Estado de Santa Catarina - PPGE/UDESC.

Professora do Departamento de Biblioteconomia e Gestão da Informação e do Programa de PósGraduação em Gestão da Informação da Universidade do Estado de Santa Catarina - UDESC.

E-mail: fernanda_faed@yahoo.com.br

\section{Resumo}

Pesquisa que objetivou que compreender (sobre) a importância do Programa de Monitoria no ensino do curso de Biblioteconomia da UDESC. A revisão bibliográfica aborda temas como: o ensino de Biblioteconomia na referida universidade, bem como aspectos pertinentes à monitoria. A metodologia apresenta característica exploratória com abordagem qualitativa. Para a coleta de dados utilizou-se entrevista e para a organização dos dados elegeu-se a categorização. Os resultados mostraram que o Programa de Monitoria é importante para o ensino no curso de Biblioteconomia da UDESC e que é mais uma forma de reforçar o ensino e aprendizagem dos alunos. Mostrou também que em alguns aspectos, como comunicação, capacitação e avaliação, o Programa requer melhorias.

Palavras-chave: Curso de Biblioteconomia. Programa de Monitoria. Monitoria. Universidade do Estado de Santa Catarina.

\begin{abstract}
This paper presents a study on the importance of the tutoring program at UDESC's Library Science program. The literature review covers topics such as: relevant aspects of monitoring and teaching at UDESC's Library Science program. The methodology employed is exploratory with a qualitative approach. In order to collect data, interviews were conducted, and to organize data the method selected was categorization. The study has shown that the tutoring program is important to teaching and learning at UDESC's Library Science program, and that it is a way of enhancing students' learning. The study has also shown that certain aspects of the tutoring program need to be improved, such as communication, training, and evaluation.
\end{abstract}

Keywords: Library Science. Monitoring program. Librarianship. Universidade do Estado de Santa Catarina.

InCID: R. Ci. Inf. e Doc., Ribeirão Preto, v. 7, n. 1, p. 131-149, mar./ago. 2016.

DOI: 10.11606/issn.2178-2075.v7i1p131-149 


\section{Introdução}

A monitoria é um dos Programas de apoio ao ensino oferecidos na Universidade do Estado de Santa Catarina (UDESC). De acordo com a resolução $\mathrm{n}^{\circ} 223$, de 2005, do Conselho Universitário (CONSUNI) da UDESC o Programa de Monitoria de Graduação tem como objetivo promover o auxílio no desenvolvimento de uma disciplina com o intuito de apoiar o ensino e a aprendizagem. Esse Programa abrange diretamente três atores: o professor, o monitor e o aluno.

O professor está apto a supervisionar o monitor no Programa de Monitoria ${ }^{1}$. O monitor realiza as atividades de monitoria como o cumprimento de horários estabelecidos, a preparação de material para as aulas, quando solicitado, e o atendimento aos alunos. E o aluno, por sua vez, tem mais uma oportunidade, através do monitor, de tirar as dúvidas que ficaram pendentes no decorrer da disciplina e relembrar os conteúdos aprendidos em sala de aula. Assim, o Programa, entre outros benefícios, promove uma integração entre os docentes e os discentes.

Para a universidade, o Programa pode ser uma oportunidade de iniciar a formação de futuros professores. A partir dele, o aluno pode interessar-se pela carreira docente, pois nesta função, o monitor observa e participa junto com o professor das atividades docentes e, com isso, existe a possibilidade de que seu interesse pela docência seja despertado.

O problema desta pesquisa centrou-se na importância do Programa para o ensino do curso de Biblioteconomia da UDESC, apontado tanto pelo professor, quanto pelo monitor e pelo aluno, e teve como objetivo geral identificar a importância que a monitoria exerce sobre o ensino de Biblioteconomia na UDESC.

O curso de Biblioteconomia da UDESC forma bibliotecários com habilitação em gestão da informação. Em seu currículo, o acadêmico cumpre uma grade diversificada com disciplinas gerais e técnicas da área, além de disciplinas voltadas para a gestão e o uso das tecnologias de informação e comunicação. Muitas dessas disciplinas apresentam características técnicas, o que dá a elas uma dinâmica bastante específica, com exercícios práticos, tornando a presença do monitor fundamental.

\footnotetext{
${ }^{1}$ Doravante, neste texto, nominado simplesmente Programa.

InCID: R. Ci. Inf. e Doc., Ribeirão Preto, v. 7, n. 1, p. 131-149, mar./ago. 2016.
} 


\section{A monitoria e o aporte na legislação brasileira}

A monitoria no Brasil, de acordo com a legislação, começou a ganhar forma no ano de 1968. No dia 28 de novembro daquele ano, foi criada a Lei $n^{\circ} 5.540$, que versa sobre o ensino superior no Brasil. O seu artigo 41 era especialmente voltado para a prática de monitoria que tinha os seguintes dizeres: “As universidades deverão criar a função de monitor para os alunos de graduação que se submeterem a provas específicas, nas quais demonstrem capacidade de desempenho em atividades técnicos didáticas de determinada disciplina”.

Este mesmo artigo apresentava a função de monitor atuante nas universidades. Para o aluno ingressar também como monitor na graduação, era necessário ter a capacidade intelectual para as práticas pedagógicas da disciplina em que pretendia ser monitor. Essa capacidade intelectual teria que ser demonstrada através de avaliação para comprovar seu rendimento e referido ingresso na função de monitor. Essa Lei também dava ao monitor, no final de suas atividades, o título para ingresso em carreira de magistério superior.

Em 11 de fevereiro de 1969, foi criado o Decreto de Lei nº 64.086, voltado ao plano de regime de trabalho dos docentes do ensino superior federal e dava outras providências. Estas “outras providências" estavam também relacionadas à prática de monitoria. O Artigo $2^{\circ}$ mencionava a criação de mil vagas para monitores.

Em 13 de março de 1970, foi criado o Decreto de Lei $n^{\circ} 66.315$ para esclarecer melhor as atividades de monitoria no ensino superior. $\mathrm{O}$ decreto compreendia seis artigos, dos quais, do primeiro ao quinto eram diretamente ligados à monitora. Abordava as funções de monitoria, os requisitos para exercê-la, a remuneração, carga horária, bem como o acompanhamento e supervisão de um professor.

Em 17 de junho de 1971 foi criado o Decreto n ${ }^{\circ} 68.771$ que altera o Decreto 66.315 de 13 de março de 1970. Este decreto tinha objetivo de alterar a redação de alguns artigos que tratavam dos requisitos, a carga horária e o valor da remuneração.

Em 31 de março de 1981, foi publicado o Decreto $\mathrm{n}^{\circ}$ 85.862. Este estabelecia que a monitoria não implicava em vínculo empregatício e que as instituições de ensino superior deveriam fixar condições para o exercício de monitor.

Segundo Dias (2007), na década de 1980 ocorreu uma descaracterização dos Programas ligados à monitoria, visto que neste período houve um crescimento considerável das pesquisas 
nas universidades brasileiras, o que aumentou também a oferta de bolsas de iniciação científica. Por esta razão, esta modalidade tornou-se bastante procurada pelos estudantes de graduação e pós-graduação.

Passado este período, o termo monitoria voltou à voga somente na década de 1990, quando, em 20 de dezembro de 1996, foi publicada a Lei de Diretrizes e Base da Educação Nacional (Lei no 9.394). Seu artigo 84 versa que: “Os discentes da educação superior poderão ser aproveitados em tarefas de ensino e pesquisa pelas respectivas instituições, exercendo funções de monitoria, de acordo com seu rendimento e seu plano de estudos". Atualmente, as regulamentações sobre monitoria são aprovadas pelos conselhos superiores das universidades.

\subsection{A introdução da monitoria nos cursos de graduação}

Entende-se por monitoria, conforme o proposto por Frison e Moraes (2010, p. 127), "uma estratégia de apoio ao ensino em que estudantes mais adiantados nos programas de formação acadêmica colaboram no processo de apropriação do conhecimento de seus colegas". Assim, o monitor é um agente a mais com quem os estudantes podem tirar suas dúvidas e com isso melhorar o seu aprendizado.

O aluno tem o monitor como um apoio a mais em sala de aula na graduação também na visão de Nunes (2007, p. 53), que afirma que

o monitor é um aluno, participa da cultura própria dos alunos, que tem diferenças com as dos professores. A interação daquele com a formação dos alunos da disciplina tende a favorecer a aprendizagem cooperativa, contribuindo com a formação dos alunos e do próprio monitor.

Essa abordagem proposta por Nunes (2007) evidencia uma ambiência mais propícia à interação. E a interação do aluno com o monitor ocasiona um ganho de ambas partes no aprendizado de determinada disciplina, visto que, pode haver uma troca de informações. $\mathrm{O}$ aluno precisa do conhecimento adquirido do monitor para solucionar uma dúvida, e este, por sua vez, precisa desse conhecimento para ajudar a solucionar a dúvida apresentada pelo aluno. Assim, ganha o aluno como uma nova oportunidade de aprender, e o monitor com a experiência de passar o conhecimento e fixar mais uma vez o conteúdo estudado da referida disciplina.

Além de realizar esse contato com os alunos, o monitor precisa cumprir suas tarefas rotineiras. Nunes (2007) também afirma que o monitor precisa relacionar a sua formação às atividades de monitoria, por consequência, o monitor tende a ficar mais de um turno dentro da 
universidade. Partindo dessa ideia, pode-se constatar que a monitoria propicia ao monitor um maior embasamento inerente aos estudos de uma determinada disciplina, ou seja, o monitor adquire um melhor conhecimento do assunto tanto para repassar aos alunos e também em seu desempenho acadêmico, bem como um maior convívio no ambiente universitário.

A função do professor no Programa é fundamental. Segundo Pereira (2007, p. 75) “o professor desempenha o papel de mediador dos conhecimentos, estabelecendo a relação entre os conhecimentos específicos e a prática pedagógica. Para isso é necessário um acompanhamento sistemático das atividades a serem desempenhadas pelo monitor”. O professor precisa ter comprometimento com o Programa e com o monitor, pois é através de uma boa orientação que ele se sente mais seguro para cumprir o seu papel.

Quando se elabora uma atividade para ser aplicada em uma determinada disciplina, o professor orientador pode discuti-la com o monitor, a fim de explicar sua interpretação sobre as questões que pretende aplicar. Nesse sentido, o professor minimiza o risco de elaborar questões fora do nível de compreensão da turma, ou seja, a relação do professor com o monitor deve ser de uma confiança mútua, de companheirismo e ética (NUNES, 2007).

Nesta esteira, Natario (2001, p. 31), lembra que

O monitor é um elo nas relações professor-aluno e aluno-aluno, tornando-se um eficiente colaborador na aprendizagem, desde que receba a orientação e condições de promover um ambiente de aprendizagem construtivo e gratificante, em que o aprendiz possa aproveitar as oportunidades para realizar interligações das noções adquiridas e insights na interpretação de problemas.

Assim, os programas de monitoria podem despertar o interesse dos alunos para uma futura carreira docente, pois ao estar em contato direto com o professor, o monitor estará vivenciando o fazer docente quando ainda é discente, colaborando com a aprendizagem dos demais alunos. O professor, por sua vez, tem uma troca com o monitor, visto que em muitas disciplinas, ele se sobrecarrega, e tendo o apoio do monitor, pode desenvolver as atividades pedagógicas com mais eficiência.

InCID: R. Ci. Inf. e Doc., Ribeirão Preto, v. 7, n. 1, p. 131-149, mar./ago. 2016. 


\subsection{A monitoria na UDESC}

As universidades brasileiras apresentam seus programas de monitoria conforme o estabelecido pelos seus conselhos superiores, onde cada universidade determina seus critérios e suas diretrizes e de acordo com a legislação vigente no país. Atualmente, na UDESC, o programa de monitoria é regido pela Resolução do CONSUNI n ${ }^{\circ} 223$, de 28 de julho de 2005. Por tratar-se da resolução que vigora até a presente data, faz-se necessário explanar com mais ênfase a referida resolução composta por 9 capítulos, 32 artigos, além de 6 anexos.

O capítulo I versa sobre concepção e objetivos do Programa e possui 3 artigos. O artigo $1^{\mathrm{o}}$ refere-se ao objetivo da monitoria. $\mathrm{O}$ artigo $2^{\circ}$ prescreve que a monitoria pode ser exercida por alunos da graduação da UDESC. O artigo $3^{\circ}$ ordena que todo monitor, obrigatoriamente, precisa de um professor orientador para atividade, visto que, o professor é o maior agente na relação de aprendizado para o monitor e é ele que responde pelas atividades desenvolvidas no programa.

A seleção, classificação e concessão para participar do Programa são apresentadas no capítulo II. Este capítulo vai do artigo $4^{\circ}$ ao artigo $8^{\circ}$, onde são abordados os pedidos de concessão de bolsa de monitoria e a indicação de que a bolsa só será oferecida quando houver recursos financeiros disponíveis ao Programa. Os artigos abordam também a duração do exercício de monitoria e reforçam o compromisso do monitor com as atividades referidas.

O capítulo III aborda as atribuições do bolsista monitor e compreende os artigos $9^{\circ}$ ao 12. $\mathrm{O}$ artigo $9^{\circ}$ refere-se às atividades que o monitor exercerá, bem como algumas vedações que remetam a atividades exclusivas de professores e o acúmulo de bolsas. Os artigos 10, 11 e 12 referem-se a outras obrigações do monitor, como assinar a folha ponto mensalmente, elaboração de relatório das atividades exercidas e apresentação do Programa em eventos específicos, caso seja selecionado.

As atribuições do professor orientador são expostas no capítulo IV que compreende os artigos 13 ao 16. O artigo 13 fixa a responsabilidade do professor orientador em supervisionar todas as atividades que o monitor vier a exercer e sua carga horária. $\mathrm{O}$ artigo 14 enumera as atividades do professor orientador. Os artigos 15 e 16 referem-se ao término das atividades de monitoria, quando o professor orientador prepara a ficha de avaliação e entrega à Direção de Ensino junto com o relatório final do bolsista monitor.

O capítulo V versa sobre o regime de trabalho do bolsista monitor, compreende do artigo

InCID: R. Ci. Inf. e Doc., Ribeirão Preto, v. 7, n. 1, p. 131-149, mar./ago. 2016. 
17 ao 20. Os artigos referem-se à carga horária de trabalho do monitor, num total 12 horas, o valor da bolsa e suas atividades, que devem ser divulgadas para que todo o corpo discente possa concorrer.

Assuntos relacionados à substituição e desistência do bolsista e cancelamento do programa estão no Capítulo VI, compreendidos do artigo 21 ao 23. O artigo 24 é o único artigo do capítulo VII, que menciona a fiscalização e à avaliação do programa de monitoria, cuja responsabilidade é da Direção de Ensino e da Pró-Reitoria de Ensino.

As definições de critérios e distribuição das vagas de monitoria estão expostas no capítulo VIII, compreendidos do artigo 25 ao 27. São alguns requisitos o elevado grau de dificuldade da disciplina, número de alunos matriculados e a relação entre teoria e prática de uma disciplina, bem como disciplinas que privilegiam a formação profissional do curso.

O capítulo IX versa sobre as disposições gerais e compreende os artigos 28 a 32 . A elaboração do edital para preenchimento de vagas de monitoria compete aos centros, que também são responsáveis pela emissão de certificados de monitoria. O seguro do monitor contra acidentes pessoais é de responsabilidade da UDESC e todos os casos omissos serão resolvidos pela Pró-Reitoria de Ensino. O artigo 32 refere-se à revogação das resoluções anteriores.

Os seis anexos contidos na resolução referem-se: ao edital de abertura de vaga; ao Programa de monitoria acadêmica; ao termo de compromisso do bolsista perante o Programa; a folha individual de frequência mensal; ao relatório final das atividades e ao relatório de avaliação anual do Programa.

Este conjunto de regras parece fazer do Programa de Monitoria as UDESC uma atividade consolidada. Neste sentido, considerou-se relevante conhecer como os três agentes envolvidos no Programa dentro do Curso de Biblioteconomia - quais sejam, o professor, o aluno e o monitor - compreendem a importância da mesma. 


\section{Procedimentos Metodológicos}

Para obtenção de dados completos optou-se por conhecer a importância atribuída à monitoria por: professores atuantes no curso de Biblioteconomia da UDESC que já participaram do Programa; monitores que participaram do Programa e acadêmicos do curso que já cursaram disciplinas com a presença do monitor em sala de aula. Assim, esta pesquisa tem três diferentes grupos de entrevistados.

O primeiro grupo entrevistado foi formado por professores do corpo docente de Biblioteconomia da UDESC que foram orientadores no programa de monitoria no ano de 2011. O referido período teve um total de 6 professores orientadores, sendo que um foi excluído pelo fato de ser o orientador deste estudo.

O segundo grupo de entrevistados foi formado por alunos que atuaram como monitores no ano de 2011 no curso de Biblioteconomia da UDESC. No ano de 2011, foram oferecidas 10 bolsas para monitores, dos quais 5 foram entrevistados. Obteve-se esse número de entrevistados, pois alguns monitores já estavam formados e não residiam mais no município, dificultando o contato para coleta de dados. Além disso, 1 era o pesquisador deste estudo.

O terceiro grupo de entrevistados foi composto por acadêmicos do Curso de Biblioteconomia no mesmo período de 2011. Para essa análise realizou-se entrevista com 2 alunos de cada disciplina contemplada com monitor.

A escolha do ano de 2011 se deu principalmente pelos pesquisadores estarem em contato com os entrevistados e terem participado do Programa no referido ano, bem como os próprios entrevistados terem amadurecido suas ideias e respondido à entrevista com opinião mais reflexiva. A coleta de dados foi realizada no segundo semestre de 2012.

Os dados coletados na entrevista foram organizados por meio da categorização, que, segundo Flick (2004, p. 189) "envolve uma comparação constante dos fenômenos, casos, conceitos e assim por diante, bem como a formulação de questões dirigidas no texto". Neste sentido, o resultado da entrevista visa a ser apresentado de uma maneira atraente ao leitor deste artigo, o que se tornou possível com a técnica da categorização. Foram criadas, desta forma, oito categorias a fim de explanar bem o tema estudado, dividindo temas pertinentes que se completam durante toda a análise.

É importante frisar que a todo pesquisador vinculado à UDESC que queira fazer uma 
pesquisa com seres humanos deve submeter seu projeto de pesquisa ao Comitê de Ética e Pesquisa em Seres Humanos (CEPSH) da universidade. Após a averiguação do CEPSH e a aprovação, tem-se uma autorização para o pesquisador conduzir a sua pesquisa. Por isso, os modelos das entrevistas das três populações deste trabalho foram encaminhados ao CEPSH e, assim, obteve-se à devida aprovação de no 109.425.

\section{Análise de Resultados}

As análises à seguir são constituídas à partir das respostas obtidas nas entrevistas realizadas com os três grupos acima mencionados. Importante frisar, no entanto, que nem todas as questões foram aplicadas a todos os grupos, respeitando-se a pertinência e características de cada um. As categorias de análise são oito, conforme vê-se no quadro 1, abaixo:

Quadro 1 - Categorias

\begin{tabular}{|c|l|l|}
\hline $\mathbf{N}^{\mathbf{0}}$ & \multicolumn{1}{|c|}{ Título } & \multicolumn{1}{|c|}{ Respondentes } \\
\hline 1 & Função do monitor & Professores e alunos \\
\hline 2 & Resolução n 223 de 2005 do CONSUNI & Professores e monitores \\
\hline 3 & A importância do programa de monitoria para professores e monitores & Professores e monitores \\
\hline 4 & A importância do programa de monitoria para os alunos & Professores, monitores e alunos \\
\hline 5 & Dificuldade nas disciplinas sem a presença de monitor & Professores, monitores e alunos \\
\hline 6 & Disciplinas a serem contempladas pelo programa de monitoria & Monitores e alunos \\
\hline 7 & A Influência do programa de monitoria no ensino de Biblioteconomia & Professores, monitores e alunos \\
\hline 8 & Melhorias para o programa de monitoria & Professores, monitores e alunos \\
\hline
\end{tabular}

Fonte: Elaborado pelos autores. 


\subsection{Função do monitor}

As respostas mostraram que a função do monitor está diretamente ligada ao auxílio ao professor e ao aluno dentro de sala de aula. Além disso, para os alunos, o monitor ajuda a tirar dúvidas em horários diferentes das aulas, principalmente em períodos de avaliações. Para o professor, o monitor atua também fora de sala de aula e ajuda na seleção de materiais e na elaboração de exercícios.

As ideias dos professores vão ao encontro às de Nunes (2007) para quem o monitor também pode participar do planejamento da aula, buscando novos textos e mídias referentes ao assunto que o professor orientador vai apresentar no decorrer da disciplina. Assim, pode apresentar novos conceitos, trazer inovações e também novas publicações na área.

Percebeu-se que as funções do monitor não se restringem em apenas fazer uma atividade no decorrer do seu trabalho. O monitor tem várias atividades que, em conjunto, tornam-se mais um recurso para o aluno melhorar sua aprendizagem.

Pode-se dizer que os entrevistados sabem quais são as funções do monitor. No entanto, ficou evidente que a grande maioria acredita que o monitor está ali somente para auxiliar o aluno e o professor. No entanto, segundo o artigo $9^{\circ}$ da Resolução 223 do CONSUNI, também pode auxiliar o corpo docente em tarefas científicas e pedagógicas, como por exemplo, dar suporte em algum evento criado pela coordenação do curso e na construção de programas que desenvolvam a aprendizagem.

\subsection{Resolução no 223 de 2005 do CONSUNI}

A categoria 2 apresenta o conhecimento que os professores e monitores têm sobre a resolução n 223 de 2005 do CONSUNI, que rege o Programa na graduação na UDESC. Nesta categoria, não foram incluídos os alunos, pois a resolução refere-se às atividades desenvolvidas apenas pelo monitor e sobre a orientação dos professores.

Apenas um professor respondeu ter conhecimento da resolução que rege todo o programa. Assim, com as respostas nesta categoria notou-se que é de desconhecimento da grande maioria a resolução $n^{\circ}$ 223/2005 - CONSUNI.

Quanto à transparência do termo de compromisso, a UDESC o disponibiliza online no seu sítio na internet, no qual apresenta a resolução na íntegra e todos os seus anexos para conhecimento de toda a comunidade. Nesse contexto, é de suma importância que os monitores e professores fiquem atentos à resolução 223/2005, visto que nela estão todas as obrigações e 
deveres, tanto para professor, monitor e UDESC, podendo o seu desconhecimento, ocasionar consequências não agradáveis.

Além disso, a Resolução no 223/2005 - CONSUNI detalha todas as atividades que o professor e o monitor devem exercer no programa de monitoria. Isso significa que a falta de entendimento e comunicação poderá acarretar o não cumprimento das atividades que a própria resolução atribui ao professor e ao monitor, como: cumprimentos de horários, bem como sua publicização aos alunos; orientação efetiva do professor às atividades do monitor; acompanhamento do professor em todas as atividades realizadas em sala de aula pelo monitor; dentre outros fatores. Sem a comunicação e o entendimento da resolução, as atividades do programa de monitoria podem ser exercidas de maneira incompleta.

\subsection{A importância do programa de monitoria para professores e monitores}

Os entrevistados responderam que o programa de monitoria é importante para o professor em vários aspectos: as turmas geralmente são cheias, então, o auxílio do monitor se torna essencial, melhorando a qualidade das aulas e a comunicação com os alunos. Outro ponto mencionado foi que os monitores proporcionam novas discussões na preparação de materiais e inserem também novas metodologias.

Os entrevistados destacaram que o programa de monitoria é importante no processo de ensino, pois, sendo monitor, é possível perceber como é a vida docente, o cotidiano de preparação de material para aulas. Além disso, o monitor também reforça seus conhecimentos e amplia seus relacionamentos junto com os docentes e os discentes.

Partindo do princípio de que as turmas têm um elevado número de alunos, Nunes (2007) afirma que é muito difícil para um professor conseguir sanar as dúvidas de todos, porque o mesmo leciona para outras turmas também. Assim, essas dúvidas devem ser divididas com o monitor. Com isso, o monitor também ganha, pois ele consegue observar o andamento do rendimento dos alunos, se o conteúdo está sendo absorvido e se o método de ensino está surtindo efeito.

Sobre essa argumentação percebeu-se que o Programa pode ser bom para todos. O professor tem um apoio a mais no seu fazer diário, e o monitor reforça seu conhecimento e adquire experiência para uma possível carreira docente. E o aluno ganha mais uma possibilidade de aprender.

InCID: R. Ci. Inf. e Doc., Ribeirão Preto, v. 7, n. 1, p. 131-149, mar./ago. 2016. 
Com as respostas dos entrevistados notou-se que monitor e o professor ganham muito com o Programa. O andamento de uma determinada disciplina é melhor dinamizado e como consequência, pode-se ter melhor resultado no aprendizado dos alunos participantes da mesma.

\subsection{A importância do programa de monitoria para os alunos}

Para os entrevistados, o Programa favorece o aluno. Para os professores a presença do monitor é importante para os alunos, já que existe mais uma pessoa em sala de aula e fora dela para o aluno recorrer quando necessita de esclarecimentos sobre a disciplina. Além desse atributo, os alunos e monitores ressaltaram também que o monitor é mais próximo do aluno que o professor, assim há uma relação mais próxima entre monitor e aluno, pois, em algumas vezes, o aluno fica mais confortável para perguntar ao monitor, e não ao professor, já que, enquanto alunos encontram-se no mesmo nível acadêmico.

Esta situação é sustentada por Santos, Boscaino e Pavão (2006, p. 8), para quem “A convivência entre aluno e aluno-monitor [...] permite que o primeiro sinta mais confortável nessa etapa do ensino superior". Quando o aluno convive com o monitor nota-se que existe um conforto maior na disciplina, pois para o aluno o monitor não deixa de ser um aluno também, que já passou por determinada disciplina e está naquele momento para trocar informações valiosas para o aprendizado na disciplina.

No Programa o monitor pode ser um minimizador dessas dificuldades que os alunos estão prestes a encontrar no decorrer da disciplina. O conteúdo é novo para os alunos e isso pode gerar dificuldades, com isso o monitor estaria a postos para auxiliar nessas possíveis dificuldades que possam surgir.

Neste contexto, Natario (2001, p. 30) enfatiza que

O monitor, conhecendo a situação de ser aluno nessa mesma disciplina, consegue captar não só as possíveis dificuldades do conteúdo ou da disciplina como um todo, mas também apresentar mais sensibilidade aos problemas e sentimentos que o aluno pode enfrentar em situações variadas como vésperas de avaliações, acúmulo de leituras e trabalhos, início e término de semestre etc.

Assim, o monitor, a partir da vivência adquirida de suas próprias experiências anteriores na disciplina, consegue identificar com mais veemência as dificuldades dos alunos.

Diante do exposto, viu-se que o Programa é vantajoso aos alunos, já que a partir dele pode-se aprofundar a compreensão dos conteúdos apresentados e discutidos em sala de aula, com o auxílio de um agente como o monitor. E o monitor é só um aluno que está avançado no 
mesmo curso. Ele não deixa de ser aluno para identificar possíveis dificuldades apresentadas. E o fato de ser aluno também pode facilitar a comunicação entre professor e aluno, tornando-a mais compreensível.

\subsection{Dificuldade nas disciplinas sem a presença de monitor}

O professor tem convicção de que com o Programa, a disciplina flui melhor, visto que em muitos casos o número de alunos em uma determinada disciplina faz com que as dúvidas apareçam com mais frequência. O que acarreta em uma dificuldade, a de conseguir atender a todos os alunos em um curto período. Isto ocorre, por exemplo, em disciplinas com carga horária elevada e com aulas práticas constantes, além de saídas de campo, resoluções de exercícios, ou seja, características que exigem uma atenção maior aos acadêmicos.

Notou-se que os alunos valorizam a presença do monitor dentro de sala de aula, principalmente em disciplinas em que ocorrem aulas práticas, com resoluções de exercícios como, Representação Descritiva e as disciplinas da área de tecnologia. Ficou evidente que em disciplinas com estas características é importante a presença do monitor.

\subsection{Disciplinas a serem contempladas pelo programa de monitoria}

A categoria 6 apresenta as disciplinas que deveriam também ser contempladas pelo Programa na opinião dos alunos e monitores. O quadro a seguir aponta as disciplinas mencionadas pelos entrevistados, e elas estão divididas de acordo com o Projeto Pedagógico do Curso de Biblioteconomia da UDESC (2007). Nele, as disciplinas estão divididas em 6 grandes grupos, sendo que na pesquisa são mencionadas disciplinas de 4 desses grupos.

Quadro 2 - Disciplinas mencionadas pelos entrevistados

\begin{tabular}{|c|c|}
\hline Fundamentação Geral & Pesquisa \\
\hline $\begin{array}{l}\text { - Lógica Aplicada à Documentação } \\
\text { - } \quad \text { História do Livro e das Bibliotecas }\end{array}$ & - Estatística \\
\hline Organização e Recuperação da Informação & Tecnologias da Informação \\
\hline $\begin{array}{ll}\text { - } & \text { Representação Descritiva III } \\
\text { - } & \text { Indexação e Resumos } \\
\text { - } & \text { Representação Temática I } \\
\text { - } & \text { Representação Temática II }\end{array}$ & $\begin{array}{l}\text { - } \text { Gerenciamento Eletrônico de Documentos } \\
\text { - } \\
\text { - } \\
\text { - } \\
\text { - Tecnolanejamento e Geração de Bases de Dados da Informação e Comunicação I } \\
\text { - Tecnologias da Informação e Comunicação II } \\
\text { Termação e Comunicação III }\end{array}$ \\
\hline
\end{tabular}

Fonte: Elaborado pelos autores.

Uma das disciplinas que foi mencionada pelos alunos é a disciplina de Estatística, InCID: R. Ci. Inf. e Doc., Ribeirão Preto, v. 7, n. 1, p. 131-149, mar./ago. 2016. 
pertencente ao grupo de disciplinas de da área de Pesquisa. Segundo Crespo (2009, p.3) “é uma parte da Matemática Aplicada que fornece métodos para a coleta, organização, descrição, análise e interpretação de dados e para a utilização dos mesmos na tomada de decisões”. De acordo com a reformulação curricular do curso (2007), a disciplina de Estatística é composta por 3 créditos com carga horária de 54h/a, oferecida na segunda fase do curso. A disciplina envolve matemática e vários alunos mencionaram ter dificuldade com cálculo, por isso é uma disciplina que deveria participar do Programa com frequência.

Outra disciplina citada foi a de Lógica Aplicada à Documentação que pertence à área de disciplinas de Fundamentação Geral. Lógica, de acordo com Keller e Bastos (2009, p. 15) “é a disciplina que trata das formas de pensamento, da linguagem descritiva do pensamento, das leis de argumentação e raciocínio corretos, dos métodos e dos princípios que regem o pensamento humano". Os alunos, segundo dados coletados nas entrevistas, apresentam dificuldades e a presença do monitor poderia ajudar no entendimento dos conteúdos.

As disciplinas da área Organização e Recuperação da Informação, que envolvem a indexação e os códigos de classificação, também foram citadas. Para Lancaster (2004, p. 1) “os processos de indexação identificam o assunto do que trata o documento". O processo de indexação, por exemplo, é algo minucioso que requer técnica para ser feito da maneira correta e os alunos sentem dificuldades em aprender os procedimentos. Por se tratar de disciplinas técnicas, a presença do monitor pode ajudar no desenvolvimento do aprendizado dos alunos.

Por fim, algumas disciplinas apontadas pelos alunos como importantes de se ter monitor são as disciplinas da área de Tecnologias da Informação. Para Rezende e Abreu (2004, p. 79) "A tecnologia da informação não deve ser trabalhada e estudada de forma isolada." As disciplinas ligadas à tecnologia no curso unem a teoria à prática em laboratório. Como uma parte é prática, as dificuldades aparecem, e em uma turma em laboratório, por exemplo, também. A elevada demanda nos esclarecimentos das dúvidas ocasiona assim, a necessidade de um monitor.

InCID: R. Ci. Inf. e Doc., Ribeirão Preto, v. 7, n. 1, p. 131-149, mar./ago. 2016. 


\subsection{A influência do programa de monitoria no ensino de Biblioteconomia}

A ação do professor em sala de aula é essencial no ensino universitário. Bastos (2010, p. 108), enfatiza que

\footnotetext{
A ação docente frente a formação profissional de alunos universitários é uma questão central da universidade. A preocupação com a presença da reflexividade crítica no interior dos cursos, na sala de aula, podem impulsionar ações que promovam uma melhor graduação dos alunos.
}

E ações como o programa de monitoria que podem apoiar uma melhor formação na graduação. Os professores frisaram que o Programa é importante para o curso de Biblioteconomia, pelo fato de existirem disciplinas muito técnicas, ocasionando muitas dúvidas aos alunos. Essas disciplinas técnicas são disciplinas essenciais para o trabalho futuro de um Bibliotecário, então o Programa de monitoria é relevante para andamento do ensino no curso.

Os monitores retratam que o programa influência de uma maneira positiva. As turmas do Curso de Biblioteconomia são relativamente grandes e o professor é um só no momento da aula. O monitor, junto com o professor, consegue interagir de uma forma mais rápida com os alunos e, como consequência, as dúvidas são esclarecidas. O monitor também pode auxiliar fora de sala de aula, que é outro complemento que fortalece o ensino do curso. Neste sentido, para Frison e Moraes (2010), é necessário que exista um monitor competente, pois ele vai atuar como um mediador da aprendizagem dos alunos. É preciso ser um monitor dedicado e que as partes envolvidas (aluno e professor) também estejam interessadas.

Para os alunos, o curso de Biblioteconomia não é um curso fácil. O Programa os ajuda de uma maneira complementar, influenciando de forma positiva. O monitor já passou por aquela disciplina, assim tem facilidade em dialogar com os alunos e solucionar possíveis dúvidas que possam surgir. Lopes (2010) ressalta que os alunos que ingressam na universidade têm experiência escolar muito distinta, uns com uma boa formação escolar e outros nem tanto. Assim, o Programa proporciona também para os alunos uma forma a mais de assimilar o conteúdo para aqueles que têm mais dificuldade com as disciplinas em estudo.

A monitoria no ensino superior contribui não somente na melhoria do ensino, mas também para um envolvimento maior entre docentes e discentes; a experiência do Programa permite o aprofundamento dos conhecimentos adquiridos na formação acadêmica e profissional dos alunos (PEREIRA, 2007).

\subsection{Melhorias para o programa de monitoria}

InCID: R. Ci. Inf. e Doc., Ribeirão Preto, v. 7, n. 1, p. 131-149, mar./ago. 2016. 
Uma das dificuldades apontadas é a comunicação entre professor e monitor. Para Díaz Bordenave (2006, p. 19) “A comunicação é uma necessidade básica da pessoa humana, do homem social". A comunicação nada mais é que o entendimento entre duas ou mais pessoas em um determinado diálogo, você se comunica para obter e passar informação (HELLER, 1999).

Freire (1988, p. 67) destaca que "O que caracteriza a comunicação enquanto este comunicar comunicando-se, é que ela é diálogo, assim como o diálogo é comunicativo”. Desse modo, o professor e o monitor vão estabelecer uma boa comunicação se os mesmos tiverem muito diálogo. É preciso preparo, planejamento e sintonia entre os dois agentes, isso acarreta um bom desenvolvimento da atividade de monitoria.

Alunos, monitores e professores, de uma maneira geral, apontaram a necessidade de uma capacitação dos monitores que venham a participar do programa. Com a capacitação os monitores estariam preparados para estar em sala de aula junto ao professor com mais naturalidade.

A carga horária da monitoria foi outro ponto mencionado. Atualmente a carga horária do programa é de 12 horas semanais contando com as horas-aulas em sala. Para alguns alunos a parte restante para atendimento extraclasse é escassa e nem sempre os monitores podem atendem em horários alternativos. O número de bolsas, segundo os respondentes, precisa ser aumentado também.

A remuneração da bolsa de monitoria também foi mencionada. Para os próprios monitores o valor da bolsa foi considerada baixa. Ao comparar a bolsa de monitoria com os estágios remunerados na área de Biblioteconomia na região onde está localizada a UDESC, notou-se que os estágios eram melhor remunerados. Isto pode gerar baixa procura para exercer a atividade de monitoria, pois os alunos acabam optando por uma melhor remuneração do que por um conhecimento a mais ingressando no Programa.

Ao final do programa de monitoria da UDESC, o monitor precisa elaborar um relatório final de todas as suas atividades que foram desenvolvidas durante o programa. Uma questão levantada por um professor foi a necessidade de o programa ter uma avaliação, no sentido de averiguar se o que está sendo desenvolvido está sendo útil ao professor, ao monitor, ao aluno e à universidade.

InCID: R. Ci. Inf. e Doc., Ribeirão Preto, v. 7, n. 1, p. 131-149, mar./ago. 2016. 
Diante das informações obtidas no decorrer desta pesquisa pode-se perceber que o programa de monitoria da UDESC é rico, mas há pontos a serem melhorados, a fim de complementar o que já é oferecido. A categoria 8 evidenciou isso, abordou melhorias que podem ser aproveitadas pelo próprio Programa.

\section{Conclusões}

O programa de monitoria da UDESC, a partir deste estudo, apresenta-se como importante para a comunidade acadêmica. Foi possível perceber que os alunos ficam mais confortáveis quando existe a presença do monitor em sala de aula para esclarecer possíveis dúvidas que surgem no decorrer da disciplina. Para o monitor é importante por ser uma experiência que pode acarretar numa futura carreira docente. E para o professor é importante pelo fato de ter alguém para auxiliar os alunos, visto que, as turmas são em geral numerosas. Com a participação no Programa, o monitor pode aprender mais, tem a possibilidade de novas formas de aprender o conteúdo que está ajudando a ministrar.

Alguns entrevistados acreditam que apesar de ser um bom Programa para a comunidade, ainda carece de melhorias em alguns pontos, como: mais bolsas de monitoria, proporcionando um número maior de disciplinas a serem contempladas no programa; aumento da carga horária do programa e a remuneração dos monitores.

As informações sobre o Programa para os monitores também poderiam ser ampliadas, principalmente sobre a resolução que rege o Programa na UDESC. A comunicação entre professor e monitor foi outro ponto citado, bem como a capacitação inicial do monitor, que é de extrema importância.

Fica evidente que o Programa de Monitoria beneficia o ensino de Biblioteconomia. Através dele, todos ganham. O professor compartilha com o monitor suas experiências ao mesmo tempo que recebe sugestões de contribuição. $\mathrm{O}$ monitor repassa aos alunos o que aprendeu quando foi aluno e pratica a atividade docente. $\mathrm{O}$ aluno tem uma possibilidade a mais de aprender o conteúdo, de reforçar tudo aquilo que está sendo passado pelo professor. Assim, o Programa de Monitoria influência de maneira positiva ao curso de Biblioteconomia, fortalecendo o ensino e promovendo interação de toda a comunidade acadêmica. 
A importância do Programa de Monitoria no ensino de Biblioteconomia da Universidade do Estado de Santa Catarina (UDESC)

\section{Referências}

BASTOS, C. C. B. C. Ação docente e a formação crítico-humanista na universidade. In: SZYMANSKI, M. L. S. (Org.). Aprendizagem e ação docente. Cascavel: Edunioeste, 2010.

BRASIL. Decreto $n^{\circ}$ 64.086, de 11 de fevereiro de 1969. Dispões sobre o regime de trabalho e retribuição do magistério superior federal, aprova programa de incentivo à implantação do regime de tempo integral e dedicação exclusiva e outras providências. Disponível em: <http://legis.senado.leg.br/legislacao/ListaPublicacoes.action?id=194894\&tipoDocumento=D EC\&tipoTexto=PUB>. Acesso em: 14 mar. 2016.

Decreto no 66.315, de 13 de março de 1970. Dispões sobre programa de participação de estudantes em trabalhos de magistérios e em outras atividades dos estabelecimentos de ensino superior federal. Disponível em:

$<$ http://legis.senado.leg.br/legislacao/ListaPublicacoes.action?id=196822\&tipoDocumento=D EC\&tipoTexto=PUB>. Acesso em: 14 mar. 2016.

Decreto no 68.771, de 17 de junho de 1971. Altera o Decreto ${ }^{\circ} 66.315$ de 13 de março de 1970. Disponível em:

$<$ http://legis.senado.leg.br/legislacao/ListaPublicacoes.action?id=198862\&tipoDocumento=D EC\&tipoTexto=PUB $>$. Acesso em: 14 mar. 2016.

Decreto no 85.862, de 31 de março de 1981. Atribui competência às instituições de ensino superior para fixar as condições de ensino superior para fixar as condições necessárias ao exercício das funções de monitoria e dá outras providências. Disponível em: $<$ http://legis.senado.leg.br/legislacao/ListaPublicacoes.action?id=126571\&tipoDocumento=D EC\&tipoTexto=PUB>. Acesso em: 14 mar. 2016.

Lei $\mathbf{n}^{\circ}$ 5540, 28 de novembro de 1968. Dispões sobre fixa norma de organização e funcionamento do ensino superior e sua articulação com a escola média, e dá outras providências. Disponível em:

$<$ http://legis.senado.leg.br/legislacao/ListaPublicacoes.action?id=102363\&tipoDocumento=L EI\&tipoTexto=PUB>. Acesso em: 14 mar. 2016.

Lei $\mathbf{n}^{\circ}$ 9.394, de 20 de dezembro de 1996. Estabelece as diretrizes e bases da educação nacional. Disponível em:

$<$ http://legis.senado.leg.br/legislacao/ListaPublicacoes.action?id=102480\&tipoDocumento=L EI\&tipoTexto=PUB >. Acesso em: 14 mar. 2016.

CRESPO, A. A. Estatística fácil. 19.ed. São Paulo: Saraiva, 2009.

DIAS, A. M. I. A monitoria como elemento de iniciação à docência: ideias para uma reflexão. In: SANTOS, M. M.; LINS, N. M. A monitoria como espaço de iniciação a docência: possibilidade e trajetórias. Natal, Rio Grande do Norte: Edufrn, 2007. Cap. 9, p. 37-44.

DIAZ BORDENAVE, J. E. O que é comunicação. São Paulo: Brasiliense, 2006.

FLICK, U. Uma introdução à pesquisa qualitativa. 2. ed. Porto Alegre: Bookman, 2004.

FREIRE, P. Extensão ou comunicação?. 10. ed. São Paulo: Paz e Terra, 1988.

FRISON, L. M. B.; MORAES, M. A. C. As práticas de monitoria como possibilitadoras dos 
processos de autorregulação das aprendizagens discentes. Poíesis Pedagógica, Goiás, v. 8, n. 2, p. 126-146, ago./dez. 2010. Disponível em:

<http://www.revistas.ufg.br/index.php/poiesis/article/view/14064>. Acesso em: 14 mar. 2016.

HELLER, R. Como se comunicar bem. São Paulo: Publifolha, 1999.

KELLER, V.; BASTOS, C. L. Aprendendo lógica. 18. ed. Petrópolis: Vozes, 2009.

LANCASTER, F. W. Indexação e resumos: teoria e prática. 2. ed. Brasília: Lemos Informação e Comunicação, 2004.

LOPES, C. S.; ESPIG, M. J. A importância da atividade do monitor na universidade: um estudo de caso na teoria da história. In: CONGRESSO DE INICIAÇÃO CIENTÍFICA, 19.; ENCONTRO DE PÓS-GRADUAÇÃO, 12.; MOSTRA CIENTÍFICA, 2., 2010, Pelotas. Anais... Pelotas: UFPel, 2010. Disponível em: <http://www.ufpel.edu.br/cic/2010/cd/pdf/CH/CH_00855.pdf $>$. Acesso em: 14 mar. 2016.

NATARIO, E. G. Programa de monitores para atuação no ensino superior: proposta de intervenção. 2001. 142 f. Tese (Doutorado) - Curso de Faculdade de Educação, Unicamp, Campinas, 2001.

NUNES, J. B. C. Monitoria Acadêmica: espaço de formação. In: SANTOS, M. M.; LINS, N. M. A monitoria como espaço de iniciação a docência: possibilidade e trajetórias. Natal: Edufrn, 2007. p. 45-57.

PEREIRA, J. D. Monitoria: uma estratégia de aprendizagem e iniciação à docência. In: SANTOS, M. M.; LINS, N. M. A monitoria como espaço de iniciação a docência: possibilidade e trajetórias. Natal: Edufrn, 2007. p. 69-80.

REZENDE, D. A.; ABREU, A. F. Tecnologia da informação aplicada a sistemas de informação empresariais: o papel estratégico da informação e dos sistemas de informação nas empresas. 4. ed. rev. ampl. São Paulo: Atlas, 2006.

SANTOS, D. F.; BOSCAINO, E. G.; PAVÃO, A. C. Avaliação da contribuição da monitoria para o desempenho do aluno de engenharia: um estudo de caso na Escola de Engenharia Mauá. In: CONGRESSO BRASILEIRO DE EDUCAÇÃO EM ENGENHARIA, 34., 2006, Passo Fundo. Anais... Passo Fundo: Ed. UPF, 2006. Disponível em:

<http://www.abenge.org.br/CobengeAnteriores/2006/artigos/1_277_749.pdf>. Acesso em: 14 mar. 2016.

UNIVERSIDADE DO ESTADO DE SANTA CATARINA. Reformulação curricular e projeto pedagógico do curso de Biblioteconomia: habilitação Gestão da Informação. Florianópolis: UDESC, 2007 Disponível em:

<http://www.faed.udesc.br/arquivos/id_submenu/108/ppc_biblio_2007.pdf>. Acesso em: 14 mar. 2016.

Resolução $\mathbf{n}^{\circ} \mathbf{2 2 3}$ - CONSUNI, 28 de julho de 2005. Dispões sobre o programa de monitoria do ensino de graduação da UDESC. Disponível em:

<http://secon.udesc.br/consuni/resol/2005/223-2005-cni.pdf>. Acesso em: 14 mar. 2016.

Artigo submetido em: 06 jan. 2016

Artigo aceito em: 18 mar. 2016

InCID: R. Ci. Inf. e Doc., Ribeirão Preto, v. 7, n. 1, p. 131-149, mar./ago. 2016. 